Proceedings of the 50th Hawaii International Conference on System Sciences | 2017

\title{
Too Big to Fail? Overcrowding a Multi-Sided Platform and Sustained Competitive Advantage
}

\author{
Pontus Huotari \\ Lappeenranta University of Technology, School of Business and Management, Finland \\ pontus.huotari@1ut.fi
}

\begin{abstract}
Multi-sided platforms are increasingly common, which is no surprise given the winner-take-all dynamics in platform-based markets. That is, the platform with the biggest installed base of buyers and sellers can arguably sustain its competitive advantage because of positive indirect network effects. We reexamine this argument with an agent-based simulation model, where we allow for variety seeking and probabilistic buyer affiliation with platforms and interactions with sellers. Against the extant literature, we show that incumbency advantage is more unlikely to last when increasing the relative number of sellers to buyers on the incumbent platform. This is because extreme competition for buyers drives sellers and hence buyers, because of positive indirect network effects, to increasingly affiliate with the uncrowded entrant platform. We thus add to the literature by explaining how sustaining an installed base advantage is contingent on avoiding overcrowding a platform with too many sellers.
\end{abstract}

\section{Introduction}

Firms are increasingly operating multi-sided platforms, where two or more different types of customers are connected together to interact on a common platform ([1], [2]). Examples include video game consoles, PC operating systems, credit cards, electronic marketplaces, social media sites, and so on (for more examples, see e.g., [3]-[6]). Moreover, operating such platforms can be highly beneficial to focal firm performance; for example, some of the most valuable firms on Earth have monetized through multisided platforms (e.g., Apple with iOS, Alphabet with Google, Microsoft with Windows OS, Amazon.com with its marketplace, and Facebook with the social media platform). Unsurprisingly, multi-sided platforms are getting increasing attention from strategic management scholars.

It has been argued that operating a multi-sided platform can result in sustained competitive advantage ([7]) — according to Van Alstyne et al. ([8], available online): "Firms that fail to create platforms and don't learn the new rules of strategy will be unable to compete for long". This proposition is based on the prevalence of positive indirect network effects in platform-based markets ([9], [10]). They imply that a bigger installed base of buyers and sellers to a platform protects it from competitive entry (see also [11], [12]). Thus, platform-based markets are also called winnertake-all markets where new buyers and sellers have little reason to support nothing but the platform with the biggest installed base of existing buyers and sellers (see e.g., [3], [13]-[15]).

Despite the appeal of the winner-take-all argument, platforms may also lose their market leadership completely or share the market with entrant platforms as observed in practice. Take for example the rapid fall of Symbian OS and the rise of iOS - and consider, on the other hand, that the other competing platform Android did not completely take over iOS either. Consequently, increasingly many scholars have questioned the prevalence of indirect network effects in explaining these unexpected and paradoxical market outcomes of platform competition (see e.g. [4], [16], [17]).

Whereas the preceding explanations on the oligopolistic outcomes of platform competition have mostly centered on sufficient platform differentiation ([10]), in this paper we take another view. In particular, we test whether an incumbent platform that has the monopoly initially (i.e., all buyers and sellers are affiliated the platform initially) will sustain its market leadership when an identical platform enters the market (e.g., with equal price and at similar technological quality). In other words, we seek to answer whether differentiating an entrant platform is necessary to overcome incumbency advantages. 
By using agent-based modeling ([18]), we show that an incumbent platform may lose its market leadership to an undifferentiated entrant platform. Specifically, the likelihood of disruption is shown to be positively related to the relative number of sellers to buyers on the incumbent platform, when assuming buyers are variety seeking and act probabilistically (see e.g., [19], [20]). Consequently, we add to the literature on two- or multi-sided platforms ([1], [2]), and platform-based markets ([4]), by elaborating on how overcrowding a platform with too many sellers can erode its competitive advantage (see e.g., [21] [23]).

\section{Theoretical background}

\subsection{Multi-sided platforms}

Multi-sided platforms are a novel organizational form, where the focal firm facilitates interactions between multiple types of customers affiliated with the platform ([2]). That is, the distinctive feature of a platform is that it does not directly interact with buyers like, say, resellers do and that are the "twin" organizational form to multi-sided platforms (for the trade-offs in choosing between the two forms, see [24]). Instead, a platform enables third-parties to directly interact with each other on the common platform, while capturing its share from third-party interactions. Third-parties may include buyers and sellers (but also, say, advertisers) that need to make platform-specific investments in order to interact (i.e., they affiliate with the platform; see an in-depth definition in [2, pp. 163-164]). To clarify, "affiliation" may imply paying an access fee to the platform whereas "interactions" between buyers and sellers involve transactions. Figure 1 visualizes the structure of a multi-sided platform.

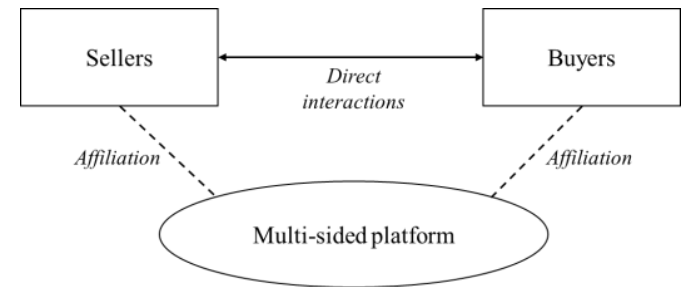

Figure 1. Multi-sided platform (adapted from [2]).

For example, Amazon.com can be considered as a multi-sided platform when it enables third-party sellers to directly sell to buyers, in which case Amazon.com charges commission fees from each transaction. On the other hand, Amazon.com is not a multi-sided platform but a reseller when it buys the products or services from third-party sellers and then sells them to buyers on its own (see e.g., [2, pp. 163165, 170-171], [25]). Another canonical example of a multi-sided platform is a video gaming console, which connects game developers and gamers, and these platforms have attracted the most attention from management scholars interested in multi-sided platforms or platform-based markets (see e.g., [4], [16], [17], [26], [27]). From the technological perspective, marketplaces like Amazon.com are obviously different to video game consoles-yet the common denominating factor for the two is the multisided market structure.

Platform-based markets are often called winnertake-all markets, where only one platform may dominate and sustain its market leadership (see e.g., [3], [13]-[15]). This is due to the prevalence of positive indirect network effects ([28]-[30]); the number of agents on one side of a platform tends to positively affect platform demand on the other market side(s), and vice versa ([2], [27]). As Hossain et al. ([10, p. 1913]; see also e.g., [9]) point out, "this is a virtuous circle with increasingly many buyers and sellers being attracted. This intuition, which is easily formalized, suggests that tipping (i.e., all players selecting the same platform) is an equilibrium in these markets." Reflecting back on Amazon.com as an example, its ability to attract third-party sellers to the platform has likely resulted in the consumers substituting other resellers and platforms with Amazon.com, and consequently more and more sellers are coming on board. Thus, the installed base of buyers and sellers have been referred to as important and inimitable resources to platforms ([7], [26]), leading to sustained competitive advantage (i.e., that a firm can sustain above average performance in competition, see e.g., [31], [32]).

According to the extant literature, the key to leveraging indirect network effects is price structure design ([1], [25], [33]-[35]). Simply put, aggressive pricing strategies that aim for subsidizing one market side usually result in getting them on board of the platform, while the other market side can be charged for above marginal cost prices due to indirect network effects, even under platform competition ([36]-[38]). For example, Amazon.com does not charge the buyers for interactions, but the sellers pay the commission fees. From the perspective of an entrant platform, it has to arguably use penetration pricing in order to "get big fast" (i.e., grow the installed base of buyers and sellers rapidly in order to leverage network effects; see e.g., [3], [17]). However, entrant platforms still face the chicken-and-egg problem, where the sellers are unwilling to come on board because of the lack of buyers - or alternatively, buyers are unwilling to come 
on board because of the lack of sellers ([39]). Therefore, an incumbent platform must not necessarily cut prices to sustain market leadership because its installed base advantage may be enough to mitigate the aggressive pricing strategies of entrants.

In addition to pricing, platform differentiation also explains platform competitiveness. A platform differentiates primarily via the sellers; for example, when it comes to video game consoles, game variety and quality differentials between competing consoles explain console sales ([17], [40], [41]). Especially the non-technological platforms such as Amazon.com depend mostly on third-party sellers in differentiating the platform, because the other factors such as technological quality of the platform are basically irrelevant (see [4]). To clarify, in case of Amazon.com, buyers need not to adopt a proprietary technology to take use of the goods or services sold, unlike when adopting, say, a video game console.

Sufficient platform differentiation may be the primary reason for why we are not always observing the winner-take-all outcome in platform-based markets ([9], [10]). In other words, the literature is rather consistent in predicting strong market concentration in platform-based markets, when platforms are undifferentiated but possess installed bases of different sizes. This is distinctive from traditional markets, where insufficient differentiation tends to imply average performance (see e.g., [42], [43]).

\subsection{Overcrowding and competitive advantage}

One concern for a platform with a big installed base of sellers is overcrowding-meaning there are too many sellers on the platform to sustain sufficient performance for all sellers. Despite the expectation that the installed base of buyers should compensate for the negative effect of within-platform competition on seller affiliation with the platform, overcrowding does deter further affiliation of sellers ([21]-[23]). To clarify, the "excess" sellers - who would be better off in terms of performance in affiliating with the entrant than the incumbent-leave the incumbent platform for the entrant. Thus, overcrowding limits platform growth and it could thus explain why no single platform takes over the entire market (but still the market would expectedly be concentrated to a degree).

However, a consequent effect due to the excess sellers leaving the incumbent platform remains unexplored. Here, we speculate that the excess sellers leaving an incumbent platform may firstly trigger further buyer affiliation with an entrant, and thus in turn promoting the sellers who were better off in affiliating with the incumbent in the first place to affiliate with the entrant as well. Should these further sellers affiliating with the entrant platform promote further buyer affiliation as well, the demand growth for the entrant platform becomes self-sustaining. These self-sustaining demand dynamics could thus erode the installed base of buyers and sellers of the incumbent platform. In other words, overcrowding could not only explain why platform-based markets do not concentrate around one platform, but also the oligopolistic market outcomes where undifferentiated platforms compete head-to-head.

Some lonely buyers or sellers need to be affiliated with the entrant platform initially, or that either of the agents were forward-looking, so that the aforementioned disruptive demand dynamics will be triggered. Forward-looking sellers could perhaps coordinate their support for the entrant platform in order to trigger buyer affiliation. However, as indicated in the preceding section, sellers tend to favor platforms with more buyers. And even if there is some evidence of forward-looking buyers (see e.g., [4], [9]), it is doubtful that they could strategically coordinate their support for the entrant platforms so as to trigger seller affiliation. On the other hand, there is some evidence in the literature that buyer affiliation precedes seller affiliation to a platform ([44]). We speculate that even if the buyers were not acting strategically when supporting an entrant platform, they could switch between competing platforms with differently sized installed bases, because they seek variety (see e.g., [45], [46]). Alternatively, borrowing from the theory of probabilistic or stochastic choice (see e.g., [20], [47], [48]), the installed base of sellers to a platform may just increase the probability of buyer affiliation. In other words, some buyers may "accidentally" choose (i.e., against their expected probabilistic choice) to affiliate with the entrant platform with the installed base disadvantage or even with no sellers. These accidental decisions may then trigger even the non-probabilistically acting sellers to increasingly favor the entrant platform.

In the following, we develop an agent-based model with which we simulate competition between an incumbent platform and an entrant, and examine the effects of overcrowding to incumbency advantage. Simulation methods are especially useful here, given the lack of theoretical and consequently empirical evidence on the hypothesized disruptive dynamics. That is, simulation helps in solidifying our theoretical understanding of an unexplored phenomenon, which is also complex enough to necessitate more than purely conceptual inquiry ([49], [50]). The next section describes the model in detail. 


\section{Methodology}

\subsection{General approach}

We simulate competition between an incumbent and an entrant platform, where the incumbent has an installed base advantage. Given our explicit interest in examining the effect of overcrowding to incumbency advantage, it is necessary to control for the other potential sources of platform competitive advantage. Ideally, the two competing platforms would be identical (e.g., they charge uniform prices, and they are technologically similar), and that the sellers for the platforms are also identical (e.g., they charge uniform prices, and they sell similar products). Thus, the buyers would be indifferent to choosing between the competing platforms, except for that the installed base of sellers on a platform positively affects buyer affiliation. Consequently, if we were to observe that the incumbent platform lost its dominant market position to the entrant, it would necessarily be due to the overcrowding effect that can ideally be controlled exogenously (i.e., by controlling for the initial number of buyers and sellers on the incumbent platform).

These aforementioned experimental conditions are basically impossible to arrange in real platform-based markets. Further, controlling for all relevant variables that might confound the effects of overcrowding to platform performance is also a non-trivial task (e.g., due to endogeneity arising from indirect network effects). Our methodological choice, agent-based modeling, is thus driven by the ease with which it is possible to set up and simulate these experimental conditions and thus examine an otherwise intractable yet an important theoretical question ([49], [50]). Moreover, it is necessary to use agent-based modeling in particular, instead of other simulation methods, because we assume variety seeking and probabilistic choices of buyers; it implies that the platform affiliation and seller interaction decisions of one buyer may differ from those of another buyer even if their expected choices were equal. To clarify further, it is especially the seller interaction decisions of buyersthat we assume to be positively affected by the preceding number of buyers for sellers (the rationale will be discussed in the model description) - that necessitates simulating buyer/seller-level behavior. The only simulation method that can account for these "bottom up" demand dynamics is agent-based modeling, where the decisions of agents are modeled at the individual level instead of the aggregate level such as in system dynamics ([18], [51], [52]).

${ }^{1}$ To clarify, here we do not subscribe to the assumptions of expected
utility theory that assumes perfect rationality of buyers (see e.g.,
With regard to the assumptions of variety seeking and probabilistic choice in particular, they reflect on the bounded rationality of buyers, or even their irrationality. It has been established long ago that real economic agents do not conform to the behavioral assumptions of rational choice models, such as consistent preferences (see e.g., [53]). In fact, not only buyers but also sellers are boundedly rational in reality; for example, sellers may not perfectly anticipate the relationship between their resources and performance ([54]), which is also one of the grounding assumptions of the resource-based view ([31], [32], [55]). We thus assume variety seeking and probabilistic choice of buyers, and also that the sellers cannot perfectly anticipate buyer affiliation with platforms. However, we still presume installed base is the major determinant of affiliation. That is, we expect buyers seeking variety only to a degree, and that most of the time they would affiliate with the platform with an installed base advantage. The same goes for sellers; we assume they do not predict buyer affiliation, but they simply tend to support the platform with the biggest installed base as it is typically (but not always, as will become evident) the one offering most utility to them (see e.g., [22]).

\subsection{The model}

Formally, there are $n_{p}=2$ platforms, $n_{b}$ buyers, and $n_{s}$ sellers in the platform-based market. At each time step, the buyers and sellers will individually decide on which of the two platforms to affiliate with. Further, each buyer will also decide on whether and with which seller to interact on the platform of choice. Thus, buyers and sellers act at the same time when affiliating with a platform. After affiliation, buyers will also choose over the sellers on the platform, while the sellers do not act anymore at the time step. This execution structure of the model conforms largely those of traditional game-theoretical models. Here, the model will be executed repeatedly for a certain number of time steps, and thus the behavior of agents, most notably the platform affiliation decisions of buyers and sellers (i.e., buyer and seller market shares of the incumbent platform), can be observed over time.

The buyer's expected utility from affiliating with a platform or interacting with a seller corresponds to the probability of choosing to affiliate with the platform or interact with the seller. ${ }^{1}$ In other words, the expected utilities of buyers range from $[0,1]$, and the greater the expected utility, the more likely it is that the buyer will affiliate with a platform or interact with

[56], [57]). Instead, our utility formulae account for the variety seeking and probabilistic behavior of buyers. 
a seller. Given we assumed platforms and sellers were identical, buyer utilities can be represented as simple functions of the installed bases, presuming each buyer will choose to affiliate with a platform and possibly interact with a seller at each time step. ${ }^{2}$ Thus, the expected utilities (probabilities) $E\left[U_{B P, t}\right]$ and $E\left[U_{B S, t}\right]$ of affiliation with a platform $P$ and interaction with a seller $S$, respectively, to a buyer $B$ at time $t$ are calculated as follows:

$$
\begin{gathered}
E\left[U_{B P, t}\right]=\frac{n_{s P, t-1}+\beta}{n_{s}+n_{p} \beta} . \\
E\left[U_{B S, t}\right]=\frac{n_{b p S, t-1}+\beta}{n_{b P, t-1}+n_{s P, t} \beta} .
\end{gathered}
$$

The $\beta$-terms in the equations 1 and 2 represent the variety seeking behavior of buyers. That is, if $\beta=0$, the buyers would not affiliate with a platform with no preceding sellers, and also they would not interact with a seller with no preceding buyers (i.e., the numerators of the equations would always equal to zero). On the other hand, the preceding buyers for a platform and a seller do not solely determine further affiliation and interaction decisions of buyers either, when $\beta>0$. Then there is a chance that the buyers choose to affiliate with another platform and interact with another seller than would be expected by the preceding number of users for the platform/seller (i.e., $n_{b P, t-1}$ and $n_{s P, t-1}$ are the number of buyers and sellers, respectively, on a platform $P$ at time $t-1$, whereas $n_{b p S, t-1}$ is the number of preceding buyers for the seller $S$ on a platform $P$ at time $t-1){ }^{3}$ For simplicity, we fix $\beta=1$ (i.e., it is a constant) in all simulations.

\footnotetext{
${ }^{2}$ If a buyer affiliates with a platform and interacts with a seller at each time step, it effectively means that they are willing to accept, say, the prices of affiliation/interaction no matter what. Thus, given the platforms and sellers are identical in terms of pricing (and other aspects), the utility formulae need not to account for prices of affiliation/interaction and the other aspects in which the buyers are indifferent to choosing over platforms/sellers. However, the implicit assumption here is that access fees, if greater than zero, are charged on an ongoing basis (e.g., subscription pricing). Thus, our model is more representative of platforms such as Amazon.com than, say, a video game console where buyers need to buy the console (i.e., make an upfront investment that adds to the switching costs) before interacting with sellers.

${ }^{3}$ It is straightforward to verify that equation 1 sums up to 1 when summing over platforms (i.e., $\sum_{p=1}^{n_{p}} E\left[U_{B P, t}\right]=1$ ). In other words, the buyers will always choose to affiliate with a platform. However, a buyer does not necessarily interact with a seller, except for when the total interactions of sellers on the platform at time $t-1$ sum up to the number of buyers on the platform at the time (i.e., $\sum_{s=1}^{n_{s P, t}} E\left[U_{B S, t}\right]=1$, if $\left.\sum_{s=1}^{n_{s P, t-1}} n_{b p S, t-1}=n_{b P, t-1}\right)$. Thus, a buyer does not necessarily interact with a seller at a time step, if some
}

Thus, from the perspective of the incumbent platform that will be having an initial installed base advantage in the simulations, there is only a slight chance that the buyers would seek variety by affiliating with the entrant. Nevertheless, it will become evident that the "accidental" entrant platform affiliation decisions of buyers due to variety seeking and probabilistic choice may trigger the self-sustaining demand dynamics leading to the incumbent disruption-even if the expected market share for the incumbent was close to $100 \%$, when $\beta=1$. $^{4}$

On the other hand, a seller makes no probabilistic platform affiliation decisions, yet their decisions are positively affected by the installed base of buyers to the platforms. Further, we assume that seller interactions with buyers are positively affected by their preceding interactions with buyers on a platform, just as if platform affiliation is positively affected by preceding affiliation. For example, in Amazon.com, a buyer can observe the other buyers' reviews of a seller before making the decision to interact. Relatedly, it has also been shown that the provision of "superstar" or "hit" software is highly important to the associated (e.g., gaming) platforms ([16], [40], [41]). Moreover, we assume that sellers do not affiliate with multiple platforms concurrently (see e.g., [37]), and that the seller "reputation" due to preceding interactions with buyers is non-transferable between platforms. Whereas neither of the assumptions is likely to hold in reality, here they are made primarily for simplicity. Further, given sellers affiliate with one platform at a time, the assumption of non-transferable reputation is also more plausible because then a seller needs to introduce itself to a "new" audience of buyers when switching to another platform. Moreover, both assumptions favor the incumbent platform, which is somewhat sought after here in the sense that especially

sellers switched platforms or if the interactions are still "building up" (i.e., when sellers have not interacted previously, as for example when a platform enters the market).

${ }^{4}$ It is straightforward to verify that the expected buyer (and hence seller) market share of the incumbent platform decreases when $\beta$ increases. As an example, if $\beta=1$ and all $n_{s}=100$ sellers were using the incumbent platform at time $t-1$ (i.e., no sellers were using the entrant platform at the time), the expected buyer market share for the incumbent platform at time $t$ is $\frac{100+1}{100+2 * 1} \approx 0.9901$. Similarly, if $\beta=100$, then the expected buyer market share is two thirds. One can analytically solve $\frac{n_{S P, t-1}+\beta}{n_{S}+n_{p} \beta}=0.5$ for $\beta$ to find out where disruption (of the buyers' side) of the incumbent platform is expected-for example, if $n_{p}=2$, it should be that $\beta=$ $\frac{\frac{1}{2} * n_{S}-n_{S P}, t-1}{1-\frac{1}{2} * n_{p}}=\frac{\frac{1}{2} * n_{S}-n_{S} P, t-1}{1-\frac{1}{2} * 2} \rightarrow \infty$, if the incumbent platform was expectedly to be disrupted on the byers' side of the platform at time $t$. Note that the formulation of equation 1 also explains why the incumbent platform does not take over the entire market of buyers initially, when the number of sellers on the platform is relatively low (see the left hand side contour plots in Figure 2). 
in such hypothetical market conditions we would expect the incumbency advantage to last (i.e., disproving this presumption would then be a strong result). Finally, we assume that the sellers can anticipate their interactions with buyers on a platform, yet they cannot anticipate the number of buyers on the platform. These latter assumptions are plausible in the sense that sellers are more likely to anticipate their own interactions than those of platforms (other than retrospectively; see e.g., [22]). Also, given the implicit assumption in the literature is that sellers cannot coordinate their platform affiliation - but rather they tend to be affiliated with the platform with the biggest installed base of buyers, other things being equal-it is even more expected that the sellers cannot anticipate demand for the platforms.

Therefore, a seller chooses to affiliate with the platform maximizing the following expected utility formula (i.e., equation 3). We define the expected utility $E\left[U_{S P, t}\right]$ of a platform $P$ to a seller $S$ at time $t$ as follows: ${ }^{5}$

$$
\begin{aligned}
& E\left[U_{S P, t}\right] \\
& =n_{b P, t-1} * \frac{n_{b p S, t-1}+\beta}{n_{b P, t-1}+n_{S P, t-1} \beta} .
\end{aligned}
$$

Finally, we impose all buyers and sellers to affiliate with the incumbent platform $(p=1)$ at time $t=0$. Then, from time $t=1$ onwards, competition between the incumbent platform and the entrant ( $p=$ 2 ) is simulated endogenously. The number of buyers and sellers in the market are also controlled for exogenously in the simulations-that is, $n_{b}=$ $[1000,2000,3000,4000,5000], \quad$ and $n_{s}=$ $[1,2,3, \ldots, 99,100]$, respectively. Due to the stochastic nature of the model, for each parameterization it will be simulated for 1000 iterations. In each iteration we collect the market share data for every $250^{\text {th }}$ time step (i.e., at times $t=[0,250,500, \ldots])$, and stop simulations at time $t=5000$.

All in all, the present model is arguably very simplistic, while still capturing the essentials of buyer and seller affiliation/interaction processes (i.e., direct and indirect network effects). It enables us to easily

\footnotetext{
${ }^{5}$ Note that the second term in the equation 3 corresponds largely to the utility formula of buyers (i.e., equation 2). However, the sellers' anticipation of future sellers on a platform (i.e., $n_{s P, t-1}$ ) is based on the preceding number of sellers on the platform, whereas the buyers observe the actual number of the sellers on the platform after platform affiliation.

${ }^{6}$ The model was implemented in AnyLogic 7.1.2

(www.anylogic.com).

7 Here, any sustained market share difference in favor of the incumbent platform implies its competitive advantage. The confidence intervals were calculated based on the non-parametric
}

evaluate the effects of overcrowding to incumbent platform competitive advantage by varying the number of buyers and sellers on the platform and observing the resulting market share outcomes over time. Note that there is no predetermined ratio of sellers to buyers on a platform that implies overcrowding - instead, overcrowding emerges endogenously in the model, or not. We will see whether it does in the following section. ${ }^{6}$

\section{Results}

To evaluate the effects of overcrowding to the sustained competitive advantage of the incumbent platform, Figure 2 indicates the median buyer and seller market shares of the incumbent platform with respect to the number of buyers and sellers in the market (or alternatively, on the incumbent platform, as all buyers and sellers affiliate with it initially), and also with respect to time. Note that each subplot is 3dimensional, where the contours represent the market shares of the incumbent platform with respect to the parameters. To clarify, the upper left and right contour plots in Figure 2 represent the median buyer and seller market shares respectively and at time $t=5000$ (i.e., at the last simulated time step). Analogously, the lower left and right contour plots represent the buyer and seller market shares respectively and over time, when the number of buyers in the market $n_{b}=1000$.

Most notably, the hatched areas in each contour plot (Figure 2) indicate the range of parameters where disruption of the incumbent platform is observed. In other words, in these areas, the lower bound of the confidence interval (at $\gamma=0.95$ confidence level) for the median market share in either side of the incumbent platform is equal to or lower than $50 \% .^{7}$

One can easily see from the upper left and right contour plots (Figure 2) that the incumbent platform is more likely to lose its market leadership until the time $t=5000$, when the relative number of sellers to buyers in the market increases. For example, when $n_{b}=1000$, the incumbent platform loses its market leadership approximately when $n_{s}>20$ until the time $t=5000$. The pace of disruption is also positively

bootstrap using 1000 bootstrap samples. Bootstrapped estimates tend to be asymptotically consistent and unbiased regardless of the underlying distribution of data ([58]), which is very useful because simulation models can easily produce non-normally distributed data (this is also the reason for measuring the median market shares instead of means) ([59]). Further, it is practically impossible to check for the distribution of data in each of the many parameterizations, and hence bootstrapping is basically a panacea in analyzing stochastic simulation data. 


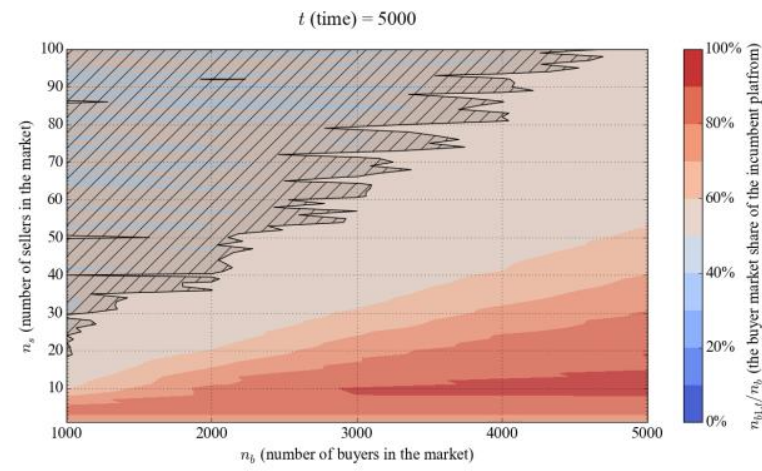

$n_{b}$ (number of buyers in the market) $=1000$

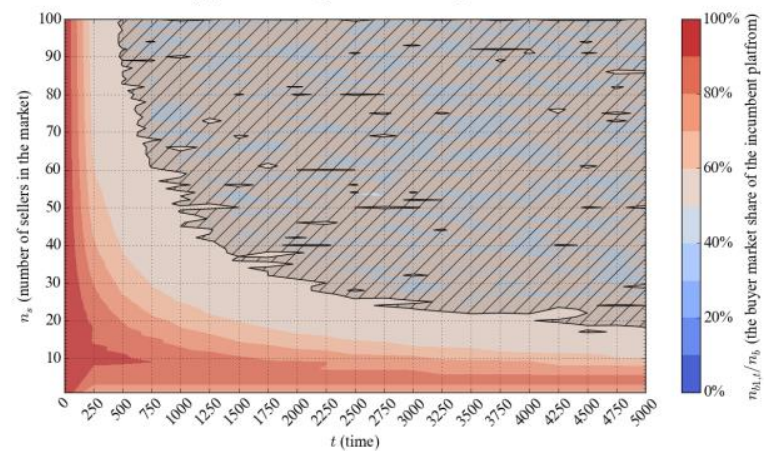

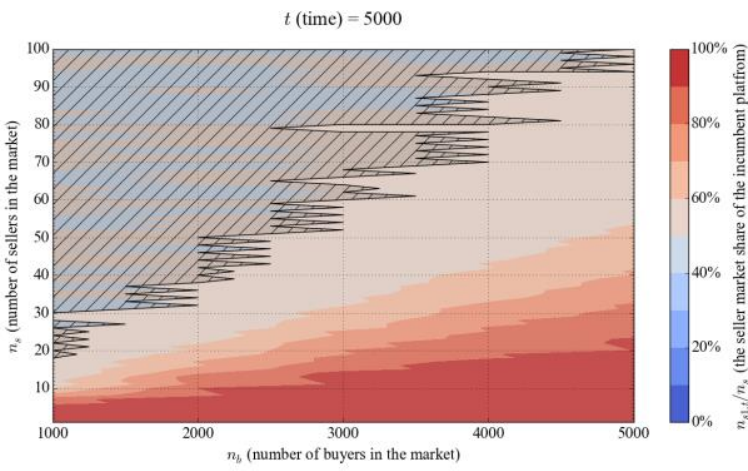

$n_{b}$ (number of buyers in the market) $=1000$

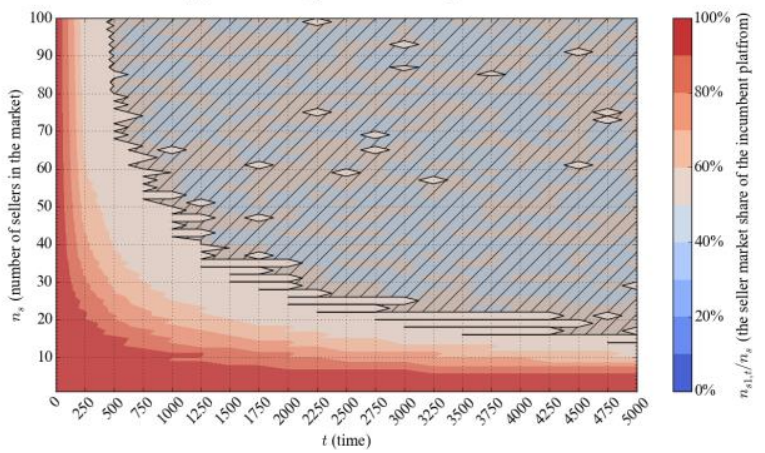

Figure 2. Median buyer (left) and seller (right) market shares of the incumbent platform with respect to the number of buyers and sellers in the market (upper), and with respect to time (lower). The hatched areas indicate the range of parameters where disruption of the incumbent platform is observed.

related to the relative number of sellers to buyers in the market (lower left and right contour plots). For example, when $n_{b}=1000$ and $n_{s}=100$, the two platforms tend to share the buyers and sellers equally approximately when $t>500$. One can also see from the left and right hand side contour plots that the disruption occurs rather uniformly on both sides of the platform.

Thus, it seems that the random events where some buyers "accidentally" affiliate with the entrant platform (i.e., against their expected probabilistic choice) are more likely to trigger further buyer and seller affiliation, leading to the self-sustaining disruptive demand dynamics, when the incumbent platform is overcrowded with too many sellers. In other words, the accidental affiliation of buyers is significantly more unlikely to trigger the selfsustaining disruptive demand dynamics, when the relative number of sellers to buyers on the incumbent platform stays at a relatively low level. ${ }^{8}$

\footnotetext{
${ }^{8}$ In fact, if the simulation model is run for long enough (e.g., tens or hundreds of thousands of time steps), the disruption seems to occur eventually, no matter what. However, it does not invalidate the aforementioned results, as it only tells us that the unlikely events can
}

\section{Discussion}

\subsection{Theoretical implications}

Multi-sided platforms are increasingly prevalent, and some of the most valuable firms on Earth (e.g., Apple, Alphabet, Microsoft, Amazon.com, and Facebook) operate them. This might not be a coincidence as platform-based markets are arguably characterized of winner-take-all dynamics. That is, the platform with the biggest installed base of buyers and sellers should sustain market leadership and basically take over the entire market, because of the prevalence of positive indirect network effects in platform-based markets ([9], [10], [13]-[15]). Thus, multi-sided platforms are becoming the next major organizational form of interest to strategic management scholars seeking to explain sustained competitive advantage ([1]-[4], [8]). Despite their appeal, however, several empirical examples illustrate how platforms cannot sustain their market leadership or how multiple platforms can compete head-to-head in platform-based

happen eventually. Due to computational limitations, we did not simulate the entire parameter space for a longer period of time than what was presented above. The present observation was based on test simulations with some selected parameters. 
markets. Thus, the intuitively sound winner-take-all argument is clearly lacking in empirical validity.

In this paper, we joined the critiques who have questioned the installed base of buyers and sellers to a platform being strategic resources, explaining sustained competitive advantage ([7], [31], [32]). Whereas the preceding explanations on the oligopolistic outcomes of platform competition have mostly centered on sufficient platform differentiation (see e.g., [4], [16], [17], [40]), we took another view, however. We were particularly interested in exploring whether an incumbent platform with an installed base advantage may lose its market leadership to an entrant that has no preceding users and is completely undifferentiated from the former. By using agentbased modeling ([18]), we showed that random and unlikely events may trigger the self-sustaining demand dynamics that lead to the erosion of incumbent platform competitive advantage due to indirect network effects. Importantly, we showed how the likelihood of the disruptive demand dynamics being triggered is positively related to the relative number of sellers to buyers on the incumbent platform.

We thus add to the literature on two- or multi-sided platforms ([1], [2]), and platform-based markets ([4]), by illustrating how the sustained competitive advantage of a platform due to indirect network effects is contingent on avoiding overcrowding. Overcrowding occurs when there are too many sellers on a platform to sustain sufficient performance for all. To the best of our knowledge-even if the extant literature acknowledges within-platform competition is detrimental to platform performance in the sense that it deters further seller affiliation ([21]-[23]) there are no existing studies explicating how overcrowding can trigger the disruptive competitive dynamics from the incumbent platform's perspective. By showing that the installed base advantage can erode "itself" - in other words, sellers may increasingly exit an overcrowded platform when more favorable platform options are available-we thus offer an important contribution to the literature that tends to picture the installed base as an inimitable and hence as a strategic resource to platforms ([7], [31], [32]). All in all, our results suggest that the oligopolistic outcomes of platform competition may simply be attributable to the lack of differentiation between platforms (see also e.g., [16]). In other words, sufficient platform differentiation may not be needed to overcome installed base advantages, as the sellers might naturally support an undifferentiated entrant platform in order to mitigate the direct negative network effects (i.e., within-platform competition).

Importantly, even if we assumed variety seeking (see e.g., [19], [45], [46]) and probabilistic platform affiliation and seller interaction decisions of buyers (see e.g., [20], [47], [48]), it does not imply that the market outcomes would be random as well. That is, the "accidental" (i.e., unexpected) entrant platform affiliation decisions of buyers were significantly more unlikely to trigger the self-sustaining disruptive demand dynamics in the simulations, when the relative number of sellers to buyers on the incumbent platform was sufficiently low. Thus, there is some validity to the winner-take-all argument. However, given the prevalence of positive indirect network effects that the winner-take-all argument builds on, more and more sellers should affiliate with the "winners". It is thus a theoretically intriguing (yet practically devastating) idea that positive indirect network effects may eventually drive the winners to become "too big to fail", no matter what, thus eroding their installed base advantage.

\subsection{Managerial implications}

The simple message of this research to practitioners is that overcrowding a platform with too many sellers should be avoided, or more generally that platforms should not exert their monopoly power over sellers "in full" (see e.g., [37]), because otherwise platform competitiveness may be hurt. Avoiding overcrowding is essentially about balancing the number of agents on each side of the platform, so that the sellers can enjoy sufficient performance and thus remain affiliated with the platform. One way to do this is to ensure platform growth on both sides of the platform. However, this may be hard in practice - if we think of the most valuable platforms today, such as Apple's iOS, the industry sources have indeed reported that the "gold rush" is over and sellers face intense competition on the platform. We would thus expect some sellers withdrawing from iOS to competing platforms, where competition is not so extreme-one possible explanation to the success of Android is that competition among sellers is not as extreme on the platform as it is on iOS. In these cases, restricting platform growth may be required to balance the market sides of the platform.

While we have not examined the strategies of platform owners to prevent overcrowding, there may be some. For example, platform owners could increase prices to sellers in order to deter further entry to the platform (i.e., to deter within-platform competition). However, such a strategy is risky, because then the entrant platforms may more easily utilize, say, penetration pricing to overcome incumbency advantages. Another strategy, as pursued by Apple, may be to adopt strict quality standards for sellers. 
This strategy may also enable platform differentiation in terms of quality.

\subsection{Limitations and future research}

There are some limitations in the present study. First, the agent-based model is highly simplistic, thus limiting the generalizability of results. For example, disruption due to overcrowding may be less common when platform switching costs are high as they were now basically ignored in the model. Thus, future research may empirically validate the theoretical findings and explore boundary conditions.

Second, we assumed buyers were seeking variety and choosing probabilistically between competing platforms and sellers. Should the reader accept these assumptions, they are not a limitation, however (see e.g., [53]). Nevertheless, it would still be interesting in the future research to explore whether the disruptive demand dynamics due to overcrowding occur in a deterministic world where buyers are rational. In particular, one could elaborate on the conditions when the forward-looking behavior of buyers (and/or sellers) could make them strategically support entrant platforms.

Moreover, we did not allow for the platforms to adapt to the changing market conditions in terms of, say, pricing. One could thus expand the analysis to account for and analyze the effectiveness of strategies (e.g., pricing) that platforms can use to counteract seller exits and hence the disruptive demand dynamics. Finally and relatedly, we imposed overcrowding by controlling for the number of buyers and sellers on the incumbent platform exogenously. One could instead endogenously model the entry of sellers to the platforms in order to understand what drives overcrowding and evaluate the platform strategies to prevent it in the first place.

\section{References}

[1] J.-C. Rochet and J. Tirole, "Two-sided markets: a progress report," RAND J. Econ., vol. 37, no. 3, pp. 645-667, 2006.

[2] A. Hagiu and J. Wright, "Multi-sided platforms," Int. J. Ind. Organ., vol. 43, pp. 162-174, 2015.

[3] T. Eisenmann, G. Parker, and M. W. Van Alstyne, "Strategies for two-sided markets," Harv. Bus. Rev., vol. 84, no. 10, pp. 92-103, 2006.

[4] F. Zhu and M. Iansiti, "Entry into platform-based markets," Strateg. Manag. J., vol. 106, no. May 2011, pp. 88-106, 2012.

[5] F. Zhu and N. R. Furr, "Products to Platforms: Making the Leap," Harv. Bus. Rev., no. April, 2016.

[6] C. Cennamo and J. Santalo, "How to Avoid Platform Traps," MIT Sloan Manag. Rev., vol. 57, no. 1, pp.
12-15, 2015.

[7] M. Sun and E. Tse, "The resource-based view of competitive advantage in two-sided markets," $J$. Manag. Stud., vol. 46, no. 1, pp. 45-64, 2009.

[8] M. W. Van Alstyne, G. G. Parker, and S. P. Choudary, "Pipelines, Platforms, and the New Rules of Strategy," Harv. Bus. Rev., no. April, 2016.

[9] J.-P. H. Dube, G. J. Hitsch, and P. K. Chintagunta, "Tipping and Concentration in Markets with Indirect Network Effects," Mark. Sci., vol. 29, no. 2, pp. 216249, 2010.

[10] T. Hossain, D. Minor, and J. Morgan, "Competing Matchmakers: An Experimental Analysis," Manage. Sci., vol. 57, no. 11, pp. 1913-1925, 2011.

[11] W. B. Arthur, "Competing Technologies, Increasing Returns, and Lock-In by Historical Events," Econ. J., vol. 99, no. 394, pp. 116-131, 1989.

[12] Lieberman, M. B, Montgomery, and D. B, "FirstMover Advantages," Strateg. Manag. J., vol. 9, no. 1 988, p. 41, 1988.

[13] M. A. Schilling, "Technology success and failure in winner-take-all markets: The impact of learning orientation, timing, and network externalities," Acad. Manag. J., vol. 45, no. 2, pp. 387-398, 2002.

[14] E. Lee, J. Lee, and J. Lee, "Reconsideration of the Winner-Take-All Hypothesis: Complex Networks and Local Bias," Manage. Sci., vol. 52, no. 12, pp. 1838-1848, Dec. 2006.

[15] D. P. McIntyre and M. Subramaniam, "Strategy in Network Industries: A Review and Research Agenda," J. Manage., vol. 35, no. 6, pp. 1494-1517, 2009.

[16] K. S. Corts and M. Lederman, "Software exclusivity and the scope of indirect network effects in the US home video game market," Int. J. Ind. Organ., vol. 27, no. 2, pp. 121-136, Nov. 2009.

[17] C. Cennamo and J. Santalo, "Platform Competition: Strategic Trade-Offs In Platform Markets," Strateg. Manag. J., vol. 34, no. 11, pp. 1331-1350, 2013.

[18] C. M. Macal and M. J. North, "Tutorial on agentbased modelling and simulation," J. Simul., vol. 4, no. 3, pp. 151-162, Sep. 2010.

[19] L. McAlister and E. Pessemier, "Variety seeking behavior: an interdisciplinary review," J. Consum. Res., pp. 311-322, 1982.

[20] F. M. Bass, A. Jeuland, and G. P. Wright, "Equilibrium Stochastic Choice and Market Penetration Theories: Derivations and Comparisons," Manage. Sci., vol. 22, no. 10, pp. 1051-1063, 1976.

[21] N. Venkatraman and C.-H. Lee, "Preferential linkage and network evolution: a conceptual model and empirical test in the U.S. video game sector," Acad. Manag. J., vol. 47, no. 6, pp. 876-892, 2004.

[22] C. E. Tucker and J. Zhang, "Growing Two-Sided Networks by Advertising the User Base: A Field Experiment," Mark. Sci., vol. 29, no. 5, pp. 805-814, 2010.

[23] K. J. Boudreau, "Let a Thousand Flowers Bloom? An Early Look at Large Numbers of Software App Developers and Patterns of Innovation," Organ. Sci., 
vol. 23, no. 5, pp. 1409-1427, 2012.

[24] A. Hagiu and J. Wright, "Marketplace or Reseller?," Manage. Sci., vol. 61, no. 1, pp. 184-203, 2015.

[25] M. Rysman, "The economics of two-sided markets," J. Econ. Perspect., vol. 23, no. 3, pp. 125-143, 2009.

[26] V. Shankar and B. L. Bayus, "Network effects and competition: an empirical analysis of the home video game industry," Strateg. Manag. J., vol. 24, no. 4, pp. 375-384, Apr. 2003.

[27] M. T. Clements and H. Ohashi, "Indirect network effects and the product cycle: Video games in the US, 1994-2002," J. Ind. Econ., vol. 53, no. 4, pp. 515542, 2005.

[28] J. Farrell and G. Saloner, "Installed Base and Compatibility: Innovation, Product Preannouncements, and Predation," Am. Econ. Rev., vol. 76, no. 5, pp. 940-955, 1986.

[29] M. L. Katz and C. Shapiro, "Technology Adoption in the Presence of Network Externalities," J. Polit. Econ., vol. 94, no. 4, pp. 822-841, 1986.

[30] S. Gupta, D. C. Jain, and M. S. Sawhney, "Modeling the evolution of markets with indirect network externalities: An application to digital television," Mark. Sci., vol. 18, no. 3, pp. 396-416, 1999.

[31] J. B. Barney, "Firm Resources and Sustained Competitive Advantage," J. Manage., vol. 17, no. 1, pp. 99-120, 1991.

[32] I. Dierickx and K. Cool, "Asset stock accumulation and sustainability of competitive advantage," Manage. Sci., vol. 35, no. 12, pp. 1504-1511, 1989.

[33] A. Hagiu, "Pricing and commitment by two-sided platforms," RAND J. Econ., vol. 37, no. 3, pp. 720737, 2006.

[34] D. S. Evans and R. Schmalensee, "The Industrial Organization of Markets with Two-Sided Platforms," Compet. Policy Int., vol. 3, no. 1, pp. 150-179, 2007.

[35] E. G. Weyl, "A Price Theory of Multi-Sided Platforms," Am. Econ. Rev., vol. 100, no. 4, pp. 1642-1672, 2010.

[36] G. G. Parker and M. W. Van Alstyne, "Two-Sided Network Effects: A Theory of Information Product Design," Manage. Sci., vol. 51, no. 10, pp. 1494 1504, 2005.

[37] M. Armstrong, "Competition in two-sided markets," RAND J. Econ., vol. 37, no. 3, pp. 668-691, 2006.

[38] U. Kaiser and J. Wright, "Price structure in two-sided markets: Evidence from the magazine industry," Int. J. Ind. Organ., vol. 24, no. 1, pp. 1-28, Jan. 2006.

[39] B. Caillaud and B. Jullien, "Chicken-and-egg: competition among intermediation service providers.," RAND J. Econ., vol. 34, pp. 309-328, 2003.

[40] J. L. G. Binken and S. Stremersch, "The Effect of Superstar Software on Hardware Sales in System Markets," J. Mark., vol. 73, no. 2, pp. 88-104, Nov. 2009.

[41] R. S. Lee, "Vertical Integration and Exclusivity in Platform and Two-Sided Markets," Am. Econ. Rev., vol. 103, no. 7, pp. 2960-3000, 2013.
[42] J. Wright, "One-sided logic in two-sided markets," Rev. Netw. Econ., vol. 3, no. 1, pp. 44-64, 2004.

[43] M. E. Porter, Competitive strategy: Techniques for analyzing industries and competitors. The Free Press, 2008.

[44] S. Stremersch, G. J. Tellis, P. H. Franses, and J. L. G. Binken, "Indirect network effects in new product growth," J. Mark., vol. 71, no. 3, pp. 52-74, 2007.

[45] J. M. Lattin and L. McAlister, "Using a VarietySeeking Model to Identify Substitute and Complementary Relationships Among Competing Products," J. Mark. Res., vol. 22, pp. 330-339, 1985.

[46] B. E. Kahn, "Consumer variety-seeking among goods and services. An integrative review," J. Retail. Consum. Serv., vol. 2, no. 3, pp. 139-148, 1995.

[47] C. F. Manski, "Maximum score estimation of the stochastic utility model of choice," J. Econom., vol. 3, no. 3, pp. 205-228, 1975.

[48] D. Mcfadden, "Econometric Models for Probabilistic Choice Among Products," J. Bus., vol. 53, no. 3, 1980.

[49] J. P. Davis, K. M. Eisenhardt, and C. B. Bingham, "Developing Theory Through Simulation Methods," Acad. Manag. Rev., vol. 32, no. 2, pp. 480-499, Apr. 2007.

[50] J. R. Harrison, G. R. Carroll, and K. M. Carley, "Simulation modeling in organizational and management research," Acad. Manag. Rev., vol. 32, no. 4, pp. 1229-1245, 2007.

[51] E. Bonabeau, "Agent-based modeling: methods and techniques for simulating human systems," Proc. Natl. Acad. Sci., vol. 99, no. suppl. 3, pp. 7280-7287, 2002.

[52] H. Rahmandad and J. Sterman, "Heterogeneity and Network Structure in the Dynamics of Diffusion: Comparing Agent-Based and Differential Equation Models," Manage. Sci., vol. 54, no. 5, pp. 998-1014, May 2008.

[53] D. Kahneman and A. Tversky, "Prospect Theory: An Analysis of Decision under Risk," Econometrica, vol. 47, no. 2, pp. 263-292, 1979.

[54] S. A. Lippman and R. P. Rumelt, "Uncertain imitability: An analysis of interfirm differences in efficiency under competition," Bell J. Econ., pp. 418138, 1982.

[55] M. A. Peteraf, "The cornerstones of competitive advantage: a resource-based view," Strateg. Manag. J., vol. 14, pp. 171-191, 1993.

[56] M. Friedman and L. J. Savage, "The Utility Analysis of Choices Involving Risk," J. Polit. Econ., vol. 56, no. 4, pp. 279-304, 1948.

[57] L. J. Neumann and O. Morgenstern, Theory of games and economic behavior. Princeton: Princeton university press, 1947.

[58] B. Efron and R. J. Tibshirani, An introduction to the bootstrap. CRC press, 1994.

[59] W. D. Kelton and A. M. Law, Simulation modeling and analysis. Boston: McGraw Hill, 2000. 